\title{
Notes on the vocalizations of Little Spiderhunter (Arachnothera longirostra)
}

Peter Boesman

In the following we briefly analyze and compare voice of the different races of Little Spiderhunter (Arachnothera longirostra). We also try to quantify the extent of any vocal differences using the criteria proposed by Tobias et al. (2010), as a support for taxonomic review. We have made use of sound recordings available on-line from Xeno Canto (XC) and Avian Vocalizations Center (AVoCet).

Our main interest is to compare Philippine races with the other taxa. Song in general of all races is quite variable, but typically consists of a rather fast repetition of a single or double note.

We have only located a few recordings from the Philippines:

flammifera (and randi?) presumed song (IBC video IBC1231141 of Desmond Allen similar)

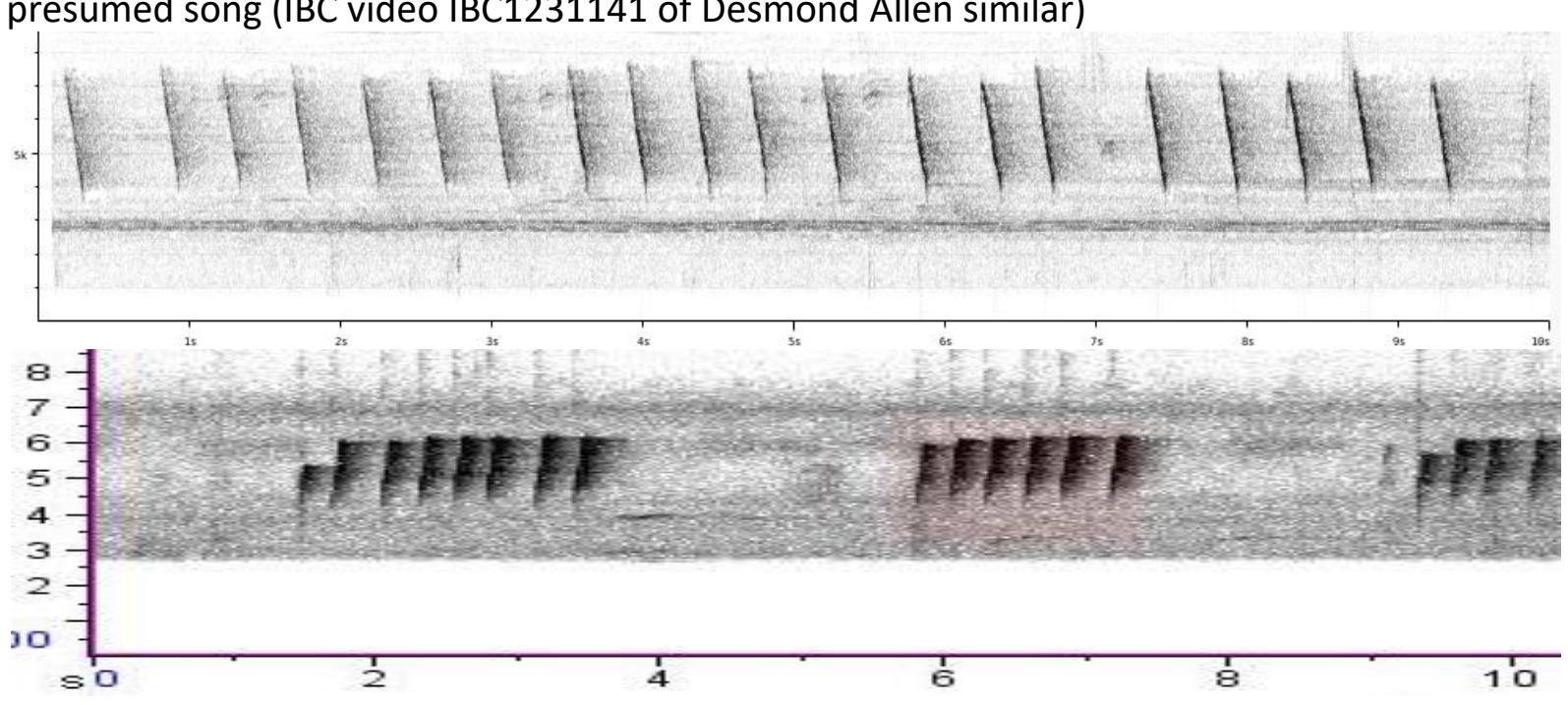

dilutior

No recordings of song available (only calls)

Other races

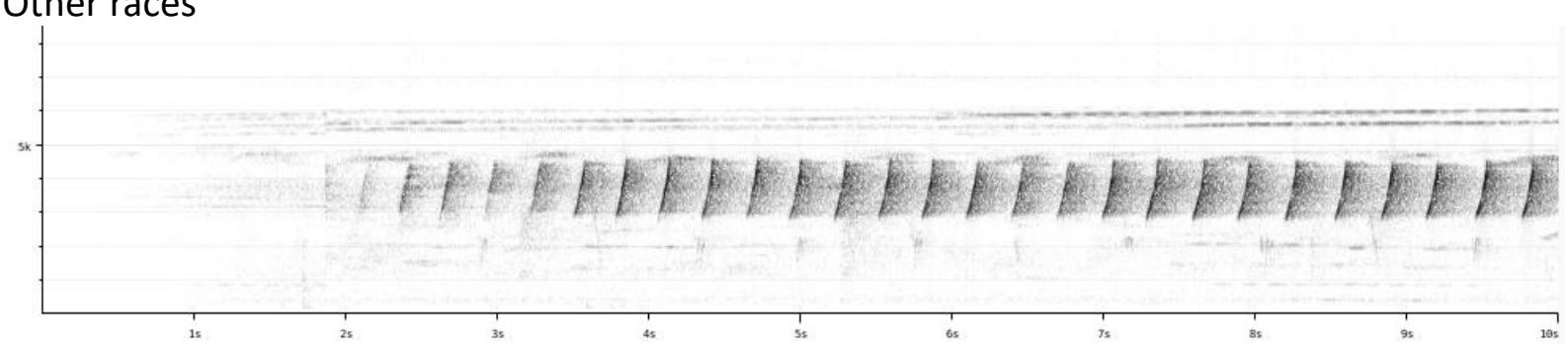


HANDBOOK OF THE

BIRDSPITHE WORLD

ORNITHOLOGICAL NOTES

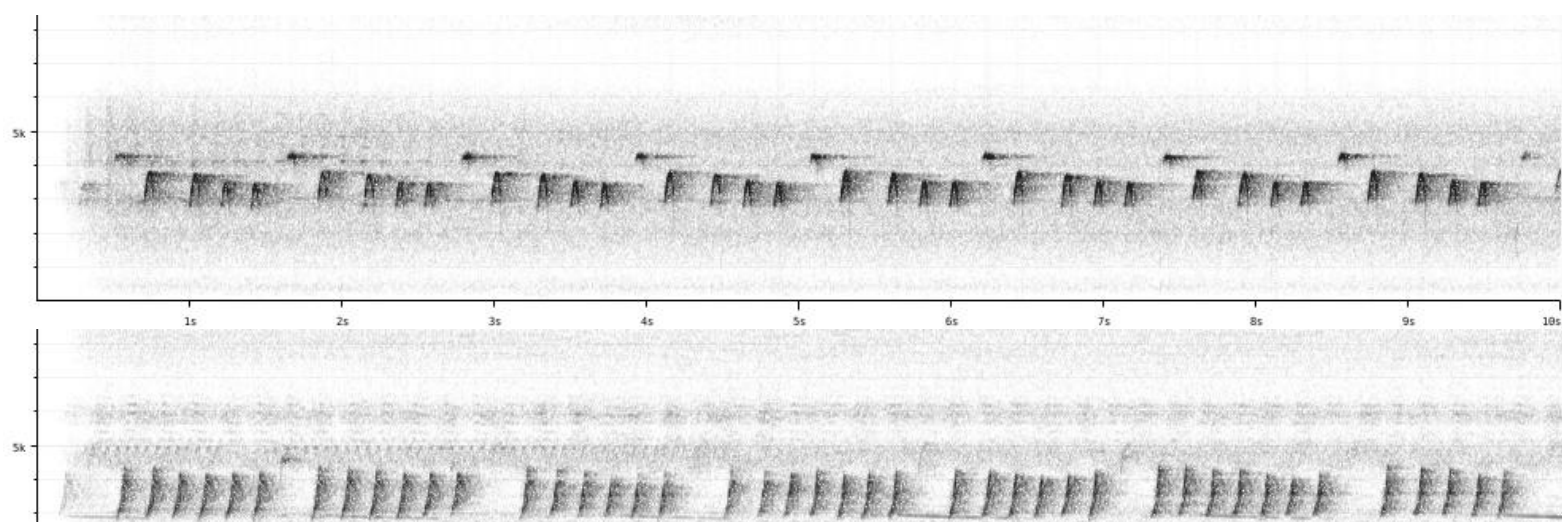

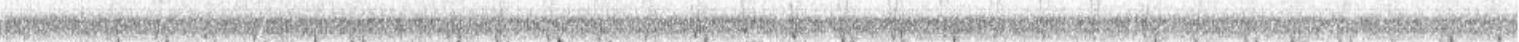

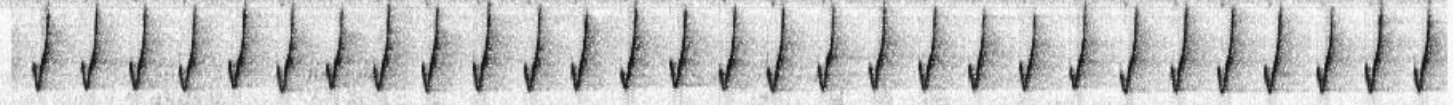

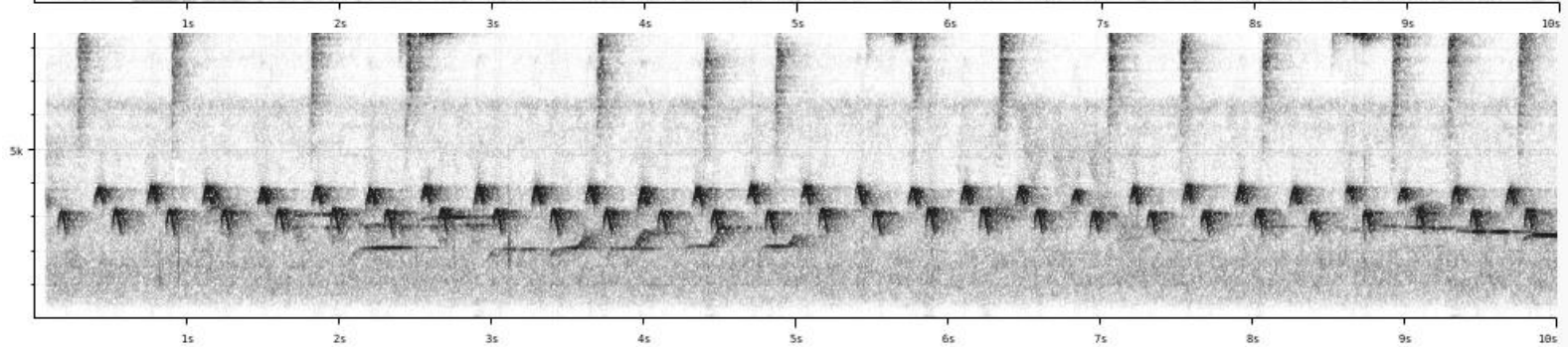

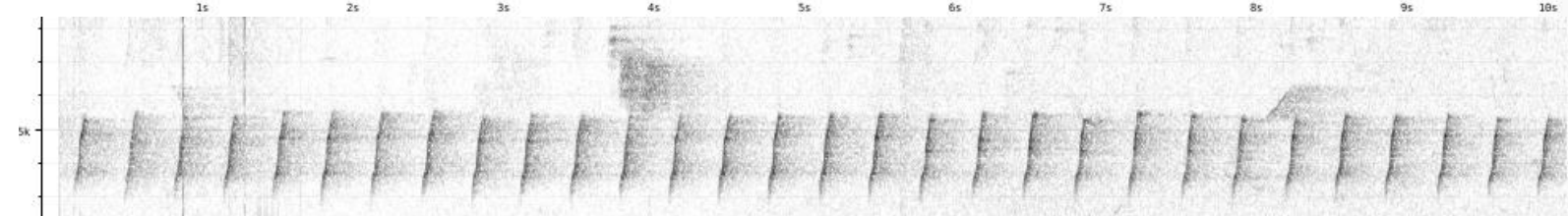

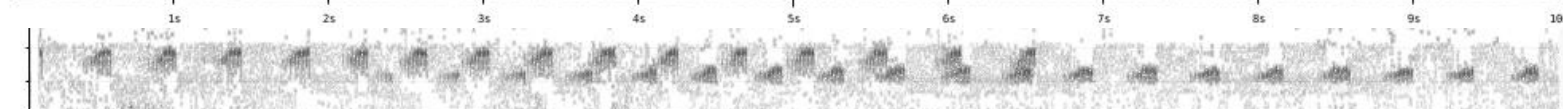

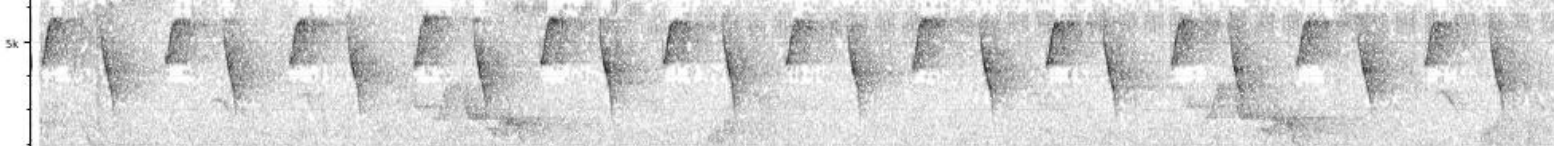

).

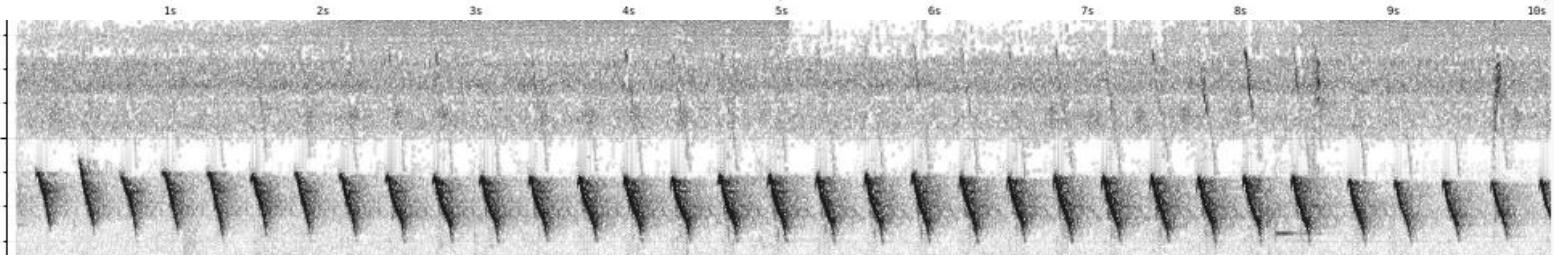


Based on four recordings of flammifera, song seems to be higher-pitched (max. frequency $6.2-7.2 \mathrm{kHz}$ vs all 'other races' $4.1-5.5 \mathrm{kHz})($ score $2-3)$. Other sound parameters similar based on these few recordings. Total vocal score thus about 2-3.

This note was finalized on 16th August 2016, using sound recordings available on-line at that moment. We would like to thank the many sound recordists who placed their recordings for this species on XC, Avocet and IBC, in particular Desmond Allen, Ross Gallardy and Pamela Rasmussen for recordings from the Philippines.

\section{References}

Tobias, J.A., Seddon, N., Spottiswoode, C.N., Pilgrim, J.D., Fishpool, L.D.C. \& Collar, N.J. (2010). Quantitative criteria for species delimitation. Ibis 152(4): 724-746.

\section{Recommended citation}

Boesman, P. (2016). Notes on the vocalizations of Little Spiderhunter (Arachnothera longirostra). HBW Alive Ornithological Note 431. In: Handbook of the Birds of the World Alive. Lynx Edicions, Barcelona. (retrieved from http://www.hbw.com/node/1271527 on 8 December 2016). 